\title{
Sex differences in the relationship between work patterns and diet in British police force employees: a nested cross-sectional study
}

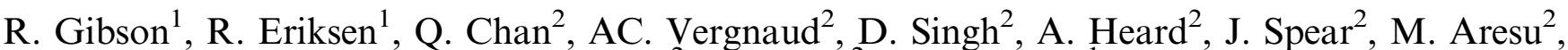 \\ D. McRobie ${ }^{2}$, P. Elliott ${ }^{2}$ and G. Frost ${ }^{1}$ \\ ${ }^{1}$ Nutrition and Dietetic Research Group, School of Medicine, Imperial College London W12 ONN and ${ }^{2}$ Department of \\ Epidemiology and Biostatistics, School of Public Health, Imperial College London W2 1PG
}

Shift workers compared to day workers are at increased risk of developing type 2 diabetes ${ }^{(1)}$ and cardiovascular diseases ${ }^{(2)}$. The aetiology for this increase in risk is thought to be due to $i$ ) shift workers making poorer lifestyle choices and $i i$ ) eating at a time that opposes our endogenous 'body clock', leading to circadian disruption. Currently 3.6 million people in the UK work shifts ${ }^{(3)}$. To date there is limited research investigating dietary behaviours and chronic metabolic disease risk in UK shift workers. The aim of this explorative study is to investigate the relationship between shift work and diet using data from the Airwave cohort, a longitudinal health monitoring study of British police force employees ${ }^{(4)}$.

Men ( $n$ 853) and women ( $n$ 376), mean age 38.4years (SD 8.6years), enrolled into the study between 2004 and 2012 , who had work pattern and dietary information available were included for cross-sectional analyses. Dietary data were collected via seven-day food diaries prior to attending a health screen. Diet quality was measured using the Mediterranean diet score ${ }^{(5)}$. Shift work exposure was determined from police radio records and a self-report questionnaire. Participants were classified into three work pattern groups: day workers (DW) (n 201), shift workers without night work (SW) (n 341), and shift workers with night work (NW) ( $n$ 687).

NW compared to DW men had a lower Mediterranean diet score (5.1 SD 1.6 vs. 5.7 SD 1.7, $p<0 \cdot 01)$ and higher food energy density $(1.7 \mathrm{kcal} / \mathrm{g} \mathrm{SD} 0.4 \mathrm{vs} .1 .6 \mathrm{kcal} / \mathrm{g} \mathrm{SD} 0.4, p<0.01)$. NW and SW compared to DW men consumed higher levels of sugar-sweetened beverages (DW $22.7 \mathrm{~g} / 1000 \mathrm{kcal}$ IQR 57.9 vs. NW $41.6 \mathrm{~g} / 1000 \mathrm{kcal}$ IQR 136, $p<0 \cdot 01$; SW $38.7 \mathrm{~g} / 1000 \mathrm{kcal}$ IQR 94.7, $p<0.05$ ). No significant differences were observed for Mediterranean diet score or energy density for women; although NW but not SW women had higher intakes of sugar-sweetened beverages compared to DW $(53 \cdot 2 \mathrm{~g} / 1000 \mathrm{kcal}$ IQR $152 \cdot 4 \mathrm{vs}$. $17 \cdot 0 \mathrm{~g} / 1000 \mathrm{kcal}$ IQR $91 \cdot 5, p<0 \cdot 01)$.

This is the first study to investigate the dietary behaviours of British police force employees. The results show that dietary differences between working pattern groups are sex specific, with men recording dietary behaviours that are established risk factors for metabolic impairment. Adherence to healthy eating guidelines is likely to be particularly important to night workers, due to emerging evidence suggesting that time-nutrient interactions impact metabolism. The results suggest that male night shift workers are an important target for workplace healthy eating programmes.

1. Pan A, Schernhammer ES, Sun Q \& Hu FB (2011) PLoS Med 8, e1001141.

2. Vyas MV, Garg AX, Iansavichus AV et al. (2012) BMJ 345, e4800.

3. Health and Safety Executive (2013) New guidance on managing shift work.

4. Elliott P, Vergnaud AC, Singh D et al. (2014) Environ Res 134C, 280-285.

5. Trichopoulou A, Costacou T, Bamia C et al. (2003) NEJM 348 (26), 2599-608. 